\title{
Gaming Duration and Preferences: Relationships with Psychiatric Health, Gaming Addiction Scores and Academic Success in High School Students
}

\author{
Ferahim Yeşilyurt $^{1}$ \\ ${ }^{1}$ Faculty of Education, Fatih Sultan Mehmet University, İstanbul, Turkey \\ Correspondence: Ferahim Yeşilyurt, Faculty of Education, Fatih Sultan Mehmet University, İstanbul, Turkey.
}

Received: June 19, 2020

Accepted: August 12, $2020 \quad$ Online Published: November 28, 2020

doi:10.5539/ies.v13n12p111

URL: https://doi.org/10.5539/ies.v13n12p111

\begin{abstract}
Problematic gaming behavior is an important problem that may lead to a recently introduced psychiatric condition named internet gaming disorder (IGD). Gaming addiction has been reported to have major influence on the lives of adolescents and young adults affected by it. Our aim was to determine relationships between gaming-related parameters, academic success, levels of depression, anxiety and stress, and gaming addiction scores. We performed a cross-sectional study comprised of 499 non-senior high school students from the Bakırköy district of Istanbul. Depression, anxiety and stress were measured with the DASS-21, gaming addiction was measured via the IGDS9-SF. A single questionnaire form was prepared to record demographics, game play behavior and preferences, DASS-21 scores and IGDS9-SF scores. Girls comprised $80.2 \%(\mathrm{n}=400)$ of the participants in this study. Eighty-eight (17.6\%) students reported that they did not play games. There was a statistically significant worsening in IGDS9 scores and all subscales of the DASS-21 with increased game playing time. Gaming addiction score was higher in those that reported being academically unsuccessful. Multivariate regression analysis revealed that the factors that increased IGDS9 scores were: time spent gaming, and preference of action, simulation or social media games. Whereas, smartphone gaming was found to be independently associated with lower IGDS9 scores. The association of higher IGDS9 scores with gaming time and preference of action, simulation and social media games, and lower scores with smartphone gaming are interesting results and may have implications in the approach to and treatment of those with IGD.
\end{abstract}

Keywords: internet gaming disorder, depression, anxiety, stress, academic success, smartphone

\section{Introduction}

Since the advent of the first commercial games in the 1970s, video games (or computer games) have become one of the most important modes of amusement (Cade \& Gates, 2017). The growth of the video game industry has surpassed the growth of any other industry in the entertainment sector, especially in the last decade (Marchand \& Hennig-Thurau, 2013; Wong, 2011). The flexibility of the industry in terms of providing universally acclaimed titles for almost all interests and any electronic platform with input and visual output devices has led to an increase in the number of persons playing video games in all age groups (Quandt, Grueninger, \& Wimmer, 2009). However, the industry is still driven by the adolescent and young adult age groups (Griffiths, Davies, \& Chappell, 2004).

Recent studies focusing on gaming, report conflicting findings regarding their influence on behavior and psychological characteristics (Cade \& Gates, 2017). While some studies have suggested a propensity for aggressive behavior among those playing violent games (Anderson \& Bushman, 2001), others have shown that video games contribute to attributes such as dexterity and decision-making (Lynch, Aughwane, \& Hammond, 2010). Although the different views on this matter remain to be discussed, it is undeniable that gaming addiction has become an important problem as it has been shown to reduce academic success, isolate individuals from social surroundings and negatively affect inter-personal relationships, particularly among adolescents and young adults (Jacobsen \& Forste, 2011; Lo, Wang, \& Fang, 2005).

It is now known that the traits of individuals with problematic levels of game playing behavior are, in essence, closely related to the characteristics of persons with other types of addictive disorders (Gentile, 2009; Kuss \& Griffiths, 2012). The DSM-V introduced the term 'internet gaming disorder' (IGD) in 2013, and this condition has been incorporated into the ICD-11 as 'gaming disorder' diagnosis (Petry \& O'Brien, 2013). After these 
recognitions, the interest in IGD (or gaming addiction) has increased with many studies aiming to determine the effects of gaming addiction on the social, personal and psychological features of those affected by the condition. Although the literature on this topic has shown adverse consequences such as skipping school, reduced academic standing and social/psychological problems including depression, anxiety and stress (Kaess et al., 2017; Kim et al., 2016; Wang, Cho, \& Kim, 2018), there is still much to be discovered on the effects of gaming addiction and its influence on young individuals, particularly regarding game playing behaviors and preferences.

Therefore, this study was planned to address the following questions: (1) Is game playing time associated with students' characteristics and their levels of gaming addiction and stress? (2) Are there any differences between academically successful and unsuccessful students in terms of gaming addiction scores? (3) Is there any association between game type and gaming addiction score?

\section{Method}

\subsection{Research Method}

A general survey model has been employed in the study. Survey models refer to research approaches that aim to describe past or existing situations. The situation, event, individual, or object related to the study is used to determine their own terms (Karasar, 2009).

\subsection{Population and Sampling}

This cross-sectional study included 499 high school students from high schools located in Bakırköy, İstanbul.

\subsection{Sampling Procedures}

We randomly selected schools from all high schools located in Bakırköy using Microsoft Excel, and we aimed to reach all students in these schools except for those in their senior year (12th grade). The students, who attended school on the day of inclusion for each high school and agreed to participate, were included into the study. Those who did not complete at least $90 \%$ of the questionnaire and those who did not fill and sign the written consent form were excluded from the study.

\subsection{Data Collection}

Data collection was performed using a questionnaire which was filled by students in their classes under the supervision of researchers. Filling the questionnaire lasted around 15-20 minutes.

\subsection{Data Collection Tools}

The questionnaire included students' age, gender, grade, school performance, DASS-21 scale and IGDS-9 scale. In addition, the students were asked what kind of games they played and preferred, how long they played on average in one day, and on what platform they played. The questionnaire included students' age, gender, grade, school performance, DASS-21 scale and IGDS-9 scale. In addition, the students were asked what kind of games they played and preferred, how long they played on average in one day, and on what platform they played.

The school performance of students was evaluated by self-assessment as a part of the questionnaire. They were asked if they felt themselves to be successful while taking into account their average GPA in comparison to their peers. Game types were categorized as sport games, car racing games, desktop games, simulation games, strategy/roleplaying games, social media games and others. They were also asked to sort game types in order from favorite type to least favorite. Game platforms were defined as: computer, gaming console, mobile phone and tablet. The IGDS9-SF is a 9-item scale that grades gaming addiction based on the respondent's gaming activities (online or offline) within the past 12 months. All questions are answered on a Likert scale ranging from 1 to 5 (never to very often). Higher scores show higher gaming addiction (Arıcak, Dinç, Yay, \& Griffiths, 2018; Pontes \& Griffiths, 2015). The DASS-21 is a 21 item scale that grades depression, anxiety and stress based on the responses to each statement. All statements are answered on a Likert scale ranging from 0 (does not apply at all) to 3 (applies very much, or most of the time). Statements 3, 5, 10,13,16, 17 and 20 assess depression, statements 2, 4, 7, 9, 15, 19 and 20 assess anxiety, and the remaining questions assess stress. In the short form, the Likert scale values are multiplied by 2 , and overall score for each scale is calculated by summing. The resultant values are used to determine severity groups (normal, mild, moderate, severe, extremely severe) (Henry \& Crawford, 2005; Y1lmaz, Boz, \& Arslan, 2017).

\subsection{Statistics and Data Analysis}

All analyses were performed on SPSS v21. The evaluation of normality of distribution was performed with the Kolmogorov-Smirnov test. Non-normally distributed variables were analyzed with the Kruskal Wallis test. For pairwise comparison, the Bonferroni correction method was used. Categorical variables were evaluated by using 
Chi-square tests. Data is given as median (minimum - maximum) for continuous variables and frequency (percentage) for categorical variables. Relationship between IGDS9-SF scores and game type preferences were assessed by calculation of the Spearman Correlation Coefficient. We performed multiple regression analysis with stepwise selection method to determine factors that were significantly effective on IGDS9-SF scores. $\mathrm{p}<0.05$ values were accepted to demonstrate statistically significant results.

\section{Results}

A total of 99 boys and 400 girls completed the questionnaire. All participants were attending 9th, 10th or 11th grade. Students were grouped based on the amount of time they spent gaming per day (none, $<1$ hour, $1-7$ hours, and $>8$ hours). Gender distribution, IGDS9 score, and all subscales of the DASS-21 score showed significant differences among these groups. Boys were found to spend significantly more time gaming compared to girls $(\mathrm{p}<0.001)$. Among the 99 boys, $32(32.3 \%)$ reported that they played games in excess of 8 hours every day; whereas, among the 400 girls, only $41(10.3 \%)$ reported this amount of time spent gaming. The scores of the IGDS9 and DASS-21 scales showed a statistically significant increase (worsening) as gaming time increased $(\mathrm{p}<0.001)$ (Table 1).

Table 1. Summary of volunteers' characteristics regarding time spent playing games per day

\begin{tabular}{|c|c|c|c|c|c|c|}
\hline & None & $<1$ hour & $1-7$ hours & $>8$ hours & Total & $\mathrm{p}$ \\
\hline $\mathrm{N}$ & 88 & 165 & 173 & 73 & 499 & N.A \\
\hline \multicolumn{7}{|l|}{ Gender } \\
\hline Girl & $84(95.45 \%)^{\mathrm{a}}$ & $148(89.70 \%)^{\mathrm{a}}$ & $127(73.41 \%)^{\mathrm{b}}$ & $41(56.16 \%)^{\mathrm{c}}$ & $400(80.16 \%)$ & \multirow{2}{*}{$<0.001$} \\
\hline Boy & $4(4.55 \%)$ & $17(10.30 \%)$ & $46(26.59 \%)$ & $32(43.84 \%)$ & $99(19.84 \%)$ & \\
\hline \multicolumn{7}{|l|}{ Grade } \\
\hline 9th & $18(20.45 \%)$ & $40(24.24 \%)$ & $37(21.39 \%)$ & $11(15.07 \%)$ & $106(21.24 \%)$ & \multirow{3}{*}{0.264} \\
\hline 10th & $16(18.18 \%)$ & $36(21.82 \%)$ & $47(27.17 \%)$ & $24(32.88 \%)$ & $123(24.65 \%)$ & \\
\hline 11 th & $54(61.36 \%)$ & $89(53.94 \%)$ & $89(51.45 \%)$ & $38(52.05 \%)$ & $270(54.11 \%)$ & \\
\hline \multicolumn{7}{|c|}{ Education Performance } \\
\hline Unsuccessful & $54(61.36 \%)$ & $112(67.88 \%)$ & $116(67.05 \%)$ & $54(73.97 \%)$ & $336(67.33 \%)$ & \multirow{2}{*}{0.405} \\
\hline Successful & $34(38.64 \%)$ & $53(32.12 \%)$ & $57(32.95 \%)$ & $19(26.03 \%)$ & $163(32.67 \%)$ & \\
\hline IGDS9 & $10(9-27) a$ & $11(9-36) b$ & $14(9-41) c$ & $21(9-45) d$ & $13(9-45)$ & $<0.001$ \\
\hline \multicolumn{7}{|l|}{ DASS-21 scores } \\
\hline Depression & $2(0-18) a$ & $2(0-18) a$ & $3(0-17) a b$ & $5(0-21) b$ & $3(0-21)$ & 0.001 \\
\hline Anxiety & $2(0-15) a$ & $2(0-19) a b$ & $4(0-19) b c$ & $5(0-19) c$ & $3(0-19)$ & $<0.001$ \\
\hline Stress & $2(0-15) a$ & $3(0-18) a$ & $4(0-16) a$ & $6(0-20) b$ & $3(0-20)$ & $<0.001$ \\
\hline \multicolumn{7}{|l|}{ DASS-21 groups } \\
\hline \multicolumn{7}{|l|}{ Depression } \\
\hline Normal & $64(72.73 \%) \mathrm{a}$ & $117(70.91 \%) \mathrm{a}$ & $103(59.54 \%) b$ & $31(42.47 \%) \mathrm{c}$ & $315(63.13 \%)$ & \multirow{5}{*}{0.001} \\
\hline Mild & $5(5.68 \%)$ & $13(7.88 \%)$ & $29(16.76 \%)$ & $13(17.81 \%)$ & $60(12.02 \%)$ & \\
\hline Moderate & $11(12.50 \%)$ & $22(13.33 \%)$ & $28(16.18 \%)$ & $15(20.55 \%)$ & $76(15.23 \%)$ & \\
\hline Severe & $8(9.09 \%)$ & $13(7.88 \%)$ & $13(7.51 \%)$ & $14(19.18 \%)$ & $48(9.62 \%)$ & \\
\hline Extremely Severe & $0(0.00 \%)$ & $0(0.00 \%)$ & $0(0.00 \%)$ & $0(0.00 \%)$ & $0(0.00 \%)$ & \\
\hline \multicolumn{7}{|l|}{ Anxiety } \\
\hline Normal & $57(64.77 \%) \mathrm{a}$ & $90(54.55 \%) \mathrm{ab}$ & $85(49.13 \%) b$ & $23(31.51 \%) \mathrm{c}$ & $255(51.10 \%)$ & \multirow{5}{*}{0.010} \\
\hline Mild & $9(10.23 \%)$ & $24(14.55 \%)$ & $25(14.45 \%)$ & $14(19.18 \%)$ & $72(14.43 \%)$ & \\
\hline Moderate & $11(12.50 \%)$ & $17(10.30 \%)$ & $26(15.03 \%)$ & $9(12.33 \%)$ & $63(12.63 \%)$ & \\
\hline Severe & $3(3.41 \%)$ & $16(9.70 \%)$ & $15(8.67 \%)$ & $9(12.33 \%)$ & $43(8.62 \%)$ & \\
\hline Extremely Severe & $8(9.09 \%)$ & $18(10.91 \%)$ & $22(12.72 \%)$ & $18(24.66 \%)$ & $66(13.23 \%)$ & \\
\hline \multicolumn{7}{|l|}{ Stress } \\
\hline Normal & $73(82.95 \%) \mathrm{a}$ & $128(77.58 \%) \mathrm{a}$ & $131(75.72 \%) \mathrm{a}$ & $42(57.53 \%) b$ & $374(74.95 \%)$ & \multirow{5}{*}{0.002} \\
\hline Mild & $6(6.82 \%)$ & $17(10.30 \%)$ & $22(12.72 \%)$ & $10(13.70 \%)$ & $55(11.02 \%)$ & \\
\hline Moderate & $6(6.82 \%)$ & $10(6.06 \%)$ & $15(8.67 \%)$ & $9(12.33 \%)$ & $40(8.02 \%)$ & \\
\hline Severe & $3(3.41 \%)$ & $9(5.45 \%)$ & $5(2.89 \%)$ & $9(12.33 \%)$ & $26(5.21 \%)$ & \\
\hline Extremely Severe & $0(0.00 \%)$ & $1(0.61 \%)$ & $0(0.00 \%)$ & $3(4.11 \%)$ & $4(0.80 \%)$ & \\
\hline
\end{tabular}

Note. Data given as median (minimum - maximum) for continuous variables and frequency (percentage) for categorical variables. 
When we evaluated the relationship between self-assessed academic performance and gaming addiction (as measured by IGDS9), we found that IGDS9 scores were significantly higher among those that reported being unsuccessful $(\mathrm{p}=0.020)$.

Table 2. IGDS9 scores regarding education performance

\begin{tabular}{lcccc}
\hline & Unsuccessful & Successful & Total & $\mathrm{p}$ \\
\hline $\mathrm{N}$ & 336 & 163 & 499 & N.A \\
IGDS9 & $13(9-45)$ & $12(9-41)$ & $13(9-45)$ & 0.020 \\
\hline
\end{tabular}

Note. Data given as median (minimum - maximum)

We then evaluated whether game preference had any influence on IGDS9 scores, we found that any type of game preference (most played games) was positively correlated with IGDS9 score ( $<<0.001$ for all). However, those that stated they preferred (and more frequently played) action and simulation games had higher correlation coefficients $(\mathrm{r}=0.406$ and $\mathrm{r}=0.395)$ compared to other game types.

Table 3. Relationship between igds9 scores and game type preferences

\begin{tabular}{|c|c|c|c|c|c|c|c|c|c|}
\hline & & $\begin{array}{c}\text { Sport } \\
\text { Games }\end{array}$ & $\begin{array}{c}\text { Car (Racing) } \\
\text { Games }\end{array}$ & $\begin{array}{l}\text { Action } \\
\text { Games }\end{array}$ & $\begin{array}{c}\text { Desktop } \\
\text { Games }\end{array}$ & $\begin{array}{c}\text { Simulation } \\
\text { Games }\end{array}$ & $\begin{array}{c}\text { Strategy/Rolling } \\
\text { Games }\end{array}$ & $\begin{array}{l}\text { Social Media } \\
\text { Games }\end{array}$ & $\begin{array}{l}\text { Other } \\
\text { Games }\end{array}$ \\
\hline $\begin{array}{l}\text { IGD } \\
\text { S9 }\end{array}$ & $r$ & 0.214 & 0.294 & 0.406 & 0.305 & 0.395 & 0.366 & 0.303 & 0.232 \\
\hline & $\mathrm{p}$ & $<0.001$ & $<0.001$ & $<0.001$ & $<0.001$ & $<0.001$ & $<0.001$ & $<0.001$ & $<0.001$ \\
\hline & $\mathrm{N}$ & 499 & 499 & 499 & 499 & 499 & 499 & 499 & 499 \\
\hline
\end{tabular}

r: Spearman Correlation Coefficient.

We performed multiple regression analysis with IGDS9-SF scores as the dependent variable, while gender, game type preference, time spent gaming, and gaming platform were defined as independent variables. We found that time spent gaming $(\mathrm{p}<0.001)$, action games $(\mathrm{p}=0.003)$, simulation games $(\mathrm{p}<0.001)$ and social media games $(\mathrm{p}=0.014)$ were significantly related with increased IGDS9 scores. Also, playing games on smartphones $(\mathrm{p}<0.001)$ was significantly related with lower IGDS9 scores compared to other gaming platforms. On the other hand, gender $(\mathrm{p}=0.290)$, sport games $(\mathrm{p}=0.253)$, car/racing games $(\mathrm{p}=0.946)$, desktop games $(\mathrm{p}=0.734)$, strategy/rolling playing games $(\mathrm{p}=0.100)$, and playing games on gaming consoles $(\mathrm{p}=0.577)$, computers $(\mathrm{p}=0.483)$ or tablets $(\mathrm{p}=0.832)$ were not found to be significant factors.

Table 4. Multiple linear regression model with IGDS9-SF as the dependent variable

\begin{tabular}{lccccccc}
\hline & $\begin{array}{c}\text { Unstandardized Beta } \\
\text { Coefficients }\end{array}$ & $\begin{array}{c}\text { Standard } \\
\text { Error }\end{array}$ & $\begin{array}{c}\text { Standardized Beta } \\
\text { Coefficients }\end{array}$ & $\begin{array}{c}95.0 \% \text { Confidence Interval } \\
\text { for Beta }\end{array}$ & $\mathrm{t}$ & $\mathrm{p}$ \\
\hline (Constant) & 6.327 & 0.953 & & 4.454 & 8.200 & 6.637 & $<0.001$ \\
Action Games & 0.684 & 0.228 & 0.133 & 0.235 & 1.133 & 2.995 & 0.003 \\
Simulation Games & 1.093 & 0.260 & 0.183 & 0.582 & 1.605 & 4.201 & $<0.001$ \\
Social Media Games & 0.517 & 0.209 & 0.098 & 0.106 & 0.928 & 2.471 & 0.014 \\
Time & 2.320 & 0.295 & 0.323 & 1.741 & 2.899 & 7.876 & $<0.001$ \\
Smartphone & -2.164 & 0.602 & -0.135 & -3.346 & -0.982 & -3.596 & $<0.001$ \\
\hline
\end{tabular}

$\mathrm{R} 2=0.342 ; \mathrm{F}=52.78 ; \mathrm{p}=<0.001$.

\section{Discussion}

Although there was no significant difference in terms of self-assessed academic performance in regard to time spent gaming, students that deemed themselves academically unsuccessful were found to have higher IGDS9 scores. IGDS9 scores showed a gradual and significant increase with increased playing time (none, $<1$ hour, $1-7$ hours and $>8$ hours). The DASS-21 scores measuring depression, anxiety and stress levels, were also found to be worse among those spending more time playing games. The percentage of students with anxiety scores conclusive for 'severe' or 'extremely severe' anxiety was of particular interest, as more than a third (37\%) of those playing games in excess of 8 hours a day were found to have severe or extremely severe anxiety levels, while the 
corresponding values of the none, $<1$ hour and $1-7$ hour groups were $12.5 \%, 21.6 \%$ and $21.4 \%$.

(1) Is game playing time associated with students' characteristics and levels of gaming addiction and stress?

Time spent playing games was associated with gender, IGDS9 score and DASS-21 scores. Boys were found to have longer game play times, while IGDS9 and DASS-21 scores indicated that students with longer gaming duration per day had higher levels of gaming addiction, and worse scores for depression, anxiety and stress.

In a recent meta-analysis, it was reported that depression and depressive behavior were rather common findings among those with IGD. Even so, studies that have reported a lack of relationship between IGD and depression do exist (King, Delfabbro, Zwaans, \& Kaptsis, 2013; Stetina, Kothgassner, Lehenbauer, \& Kryspin-Exner, 2011). Although data is limited regarding the assessment of causes leading to problematic gaming levels and associations with depression, a study by Gentile et al. showed that depressive symptoms had become an issue only after problematic levels of gaming started, and only progressed with worsening of gaming behavior (D. A. Gentile et al., 2011). This finding seems to support the suggestion that problematic levels of gaming may lead to depression, rather than the presence of a bi-directional relationship. However, a very detailed longitudinal study on this topic which assessed patients with IGD in a 4-year period, suggested that IGD and depression were influential on each other, possibly leading to a vicious cycle of comorbidity (Liu et al., 2018). Our data does not enable the determination of causal relationships between depression and gaming addiction, as is the case with the majority of studies on this field due to their cross-sectional nature; thus, it is evident that further studies on this field that perform psychological assessments and determine the underlying causes for depression in patients with IGD are required.

The relationship between IGD and anxiety appears to be a more direct one, as the literature on this topic is seemingly unanimous in terms of demonstrating increased anxiety levels (both trait and state anxiety) in those with IGD (Kim et al., 2016; King \& Delfabbro, 2016; Männikkö, Billieux, \& Kääriäinen, 2015; Vadlin, Åslund, Hellström, \& Nilsson, 2016). Our findings were no different, as $37 \%$ of students with a game playing duration of 8 hours or more (per day) had severe or extremely severe levels of anxiety, which was almost double the percentage of any other group. However, it is also important to state that anxiety scores were increased throughout our sample. For instance, while there were no students with extremely severe depression and only a few with extremely severe stress levels in all groups, $9.1 \%$ of students that did not play any games were found to have extremely severe anxiety levels. Therefore, we believe that the relationship between anxiety and IGD should be evaluated with care as this age group appears to have increased levels of anxiety at baseline when measured with DASS-21. Further studies may also benefit from the use of a better anxiety scale in terms of reflecting adolescents' anxiety levels.

In regard to stress, our findings indicate that increased time spent with gaming was associated with higher levels of stress, as measured by the DASS-21. Several studies on this topic also reported that young persons with IGD had increased stress (Kim, Namkoong, Ku, \& Kim, 2008; Paulus, Ohmann, Von Gontard, \& Popow, 2018; Subramaniam et al., 2016).

(2) Are there any differences between academically successful and unsuccessful students in terms of gaming addiction scores?

In the current study, students reporting that they felt themselves to be unsuccessful had significantly worse gaming addiction as shown by higher IGDS9 scores. The literature on this topic can be considered to be mostly one-sided, patients with IGD have been reported to have little regard for their health, academic success and social relationships, leading to significantly reduced academic success and social isolation (Griffiths, Kuss, \& King, 2012; Sublette \& Mullan, 2012; Toker \& Baturay, 2016). However, there are also studies indicating that, although academic success and gaming addiction scores were negatively correlated, further analyses demonstrated the lack of any significant effect size (Sahin, Gümüş, \& Tofur, 2014). Further, in a study performed in college students, although game playing time was not found to influence GPA, those who stated they played games were found to have lower GPA than their peers who did not play games (Wright, 2011). Therefore, although the great majority of published data indicates that academic performance is negatively affected by problematic gaming, it is apparent that further studies are needed to determine the underlying effects and results.

(3) Is there any association between game type and gaming addiction score?

Gaming addiction scores were found to be positively correlated with all game types played/preferred by the students, suggesting that preferred game type was not effective on addiction development. However, multiple regression analysis revealed that the parameters independently associated with increased IGDS9 scores were: time spent gaming and the preference of action, simulation and social media games. Interestingly, preferring to play games on smartphones was associated with lower gaming addiction score. However, gender, preference of other 
game types and preferred gaming platform(s) were not associated with gaming addiction.

It is believed that the characteristics of game types are influential on addictive behavior. Specific game characteristics or 'elements', such as presence of violence, multiplayer games, reward systems, social interactions within games, promotion of an 'involvement' feeling, and the chance for unlimited progression, have all been associated to addictive behavior development and IGD in various studies (Eichenbaum, Kattner, Bradford, Gentile, \& Green, 2015; Haagsma, Caplan, Peters, \& Pieterse, 2013; Hartmann, Jung, \& Vorderer, 2012; King, Delfabbro, Griffiths, \& Gradisar, 2011). However, the fact that many of these elements are present in various games and genres -regardless of the actual game type- make it very difficult to pinpoint an exact association between one particular characteristic and the propensity for addictive behavior towards gaming.

Despite these difficulties, addiction to massively multiplayer online role-playing games (MMORPGs) was found to be associated with several factors, including curiosity towards the game, role-playing elements, obligation to continue pursuing 'rewards', the rewards themselves, and a sense of belonging. Interestingly, in contrast to our findings, playing time was found to be unassociated with MMORPG addiction (Hsu, Wen, \& Wu, 2009). In other studies, factors that increased the possibility of gaming addiction were found to be: possessing a gaming console, handheld gaming device and high quality internet connection (Frölich et al., 2016; Karaoğlan-Yılmaz, Yılmaz, Teker, \& Keser, 2014). Although we did not assess the quality of internet access, our results with gaming platforms were in contrast with these suggestions. Moreover, we found that gaming on a smartphone was associated with lower IGDS9 score, which is a remarkable result on its own merit; however, a direct comparison may be erroneous, as smartphone gaming cannot be considered the same as the possession of a handheld gaming device. Furthermore, the majority of our participants were girls, and several studies have shown fundamental physiological differences between males and females in terms of gaming behavior and the use of electronic devices and devices designed for gaming (Hoeft, Watson, Kesler, Bettinger, \& Reiss, 2008; Kuss \& Griffiths, 2012). The reduction of IGDS9 scores in those that game on their smartphones may be crucial in terms of providing treatment options to individuals with IGD. Although it is early to arrive on conclusions regarding this matter, further studies must be performed to determine whether patients with IGD can be 'weaned' off from gaming via the recommendation of smartphone gaming as a short-term measure. To conclude, we believe that further studies are required to assess the role of gaming platforms (or devices) on the development and progression of addictive behavior and IGD, particularly due to our results indicating that smartphone gaming was not influential on gaming addiction score.

\section{Limitations}

The limitations of this study include (1) the low number of male students in which IGD is more likely to develop (Hyun et al., 2015), (2) the fact that game groups did not include separate types for MOBA and MMORPG games, which are very popular game types that may have required separation for better assessment of results, (3) not performing diagnostic studies for IGD according to DSM criteria, and (4) the lack of psychological assessments which may have been useful in identifying whether gaming and play times were a result of other problems that also influence characteristics such as depression, anxiety and stress. However, in one study, no relationship between problematic gaming and any psychiatric disorders were found (Frölich et al., 2016).

\section{Conclusion}

The relationships between gaming duration and parameters such as depression, anxiety, stress and gaming addiction scores appear to be rather significant in our group of high school students. Considering that time spent gaming, and preference of action, simulation and social media games were found to be independently associated with higher IGDS9 scores which were also found to be higher in those that reported being unsuccessful, we believe that gaming duration and game types played by high school students should be closely controlled. Finally, the fact that smartphone gaming was found to reduce IGDS9 scores is an extremely interesting finding which requires further studies for confirmation and assessment of its role in gaming behavior.

\section{References}

Anderson, C. A., \& Bushman, B. J. (2001). Effects of Violent Video Games on Aggressive Behavior, Aggressive Cognition, Aggressive Affect, Physiological Arousal, and Prosocial Behavior: A Meta-Analytic Review of the Scientific Literature. Psychological Science, 12(5), 353-359.

Arıcak, O. T., Dinç, M., Yay, M., \& Griffiths, M. D. (2018). Adapting the short form of the internet gaming disorder scale into Turkish: Validity and reliability. Addicta: The Turkish Journal on Addictions.

Cade, R., \& Gates, J. (2017). Gamers and video game culture: An introduction for counselors. The Family Journal, 25(1), 70-75. https://doi.org/10.1177/1066480716679809

Eichenbaum, A., Kattner, F., Bradford, D., Gentile, D. A., \& Green, C. S. (2015). Role-playing and real-time 
strategy games associated with greater probability of Internet gaming disorder. Cyberpsychology, Behavior, and Social Networking, 18(8), 480-485. https://doi.org/10.1089/cyber.2015.0092

Frölich, J., Lehmkuhl, G., Orawa, H., Bromba, M., Wolf, K., \& Görtz-Dorten, A. (2016). Computer game misuse and addiction of adolescents in a clinically referred study sample. Computers in Human Behavior, 55, 9-15. https://doi.org/10.1016/j.chb.2015.08.043

Gentile, D. (2009). Pathological video-game use among youth ages 8 to 18: A national study. Psychological science, 20(5), 594-602. https://doi.org/10.1111/j.1467-9280.2009.02340.x

Gentile, D. A., Choo, H., Liau, A., Sim, T., Li, D., Fung, D., \& Khoo, A. (2011). Pathological video game use among youths: a two-year longitudinal study. Pediatrics, 127(2), e319-e329. https://doi.org/10.1542/peds.2010-1353

Griffiths, M. D., Davies, M. N., \& Chappell, D. (2004). Online computer gaming: a comparison of adolescent and adult gamers. Journal of adolescence, 27(1), 87-96.

Griffiths, M. D., Kuss, D. J., \& King, D. L. (2012). Video game addiction: Past, present and future. Current Psychiatry Reviews, 8(4), 308-318. https://doi.org/10.2174/157340012803520414

Haagsma, M. C., Caplan, S. E., Peters, O., \& Pieterse, M. E. (2013). A cognitive-behavioral model of problematic online gaming in adolescents aged 12-22 years. Computers in Human Behavior, 29(1), 202-209. https://doi.org/10.1016/j.chb.2012.08.006

Hartmann, T., Jung, Y., \& Vorderer, P. (2012). What determines video game use? Journal of media psychology. https://doi.org/10.1027/1864-1105/a000059

Henry, J. D., \& Crawford, J. R. (2005). The short-form version of the Depression Anxiety Stress Scales (DASS-21): Construct validity and normative data in a large non-clinical sample. British journal of clinical psychology, 44(2), 227-239. https://doi.org/10.1348/014466505X29657

Hoeft, F., Watson, C. L., Kesler, S. R., Bettinger, K. E., \& Reiss, A. L. (2008). Gender differences in the mesocorticolimbic system during computer game-play. Journal of psychiatric research, 42(4), 253-258. https://doi.org/10.1016/j.jpsychires.2007.11.010

Hsu, S. H., Wen, M.-H., \& Wu, M.-C. (2009). Exploring user experiences as predictors of MMORPG addiction. Computers \& Education, 53(3), 990-999. https://doi.org/10.1016/j.compedu.2009.05.016

Hyun, G. J., Han, D. H., Lee, Y. S., Kang, K. D., Yoo, S. K., Chung, U.-S., \& Renshaw, P. F. (2015). Risk factors associated with online game addiction: a hierarchical model. Computers in Human Behavior, 48, 706-713. https://doi.org/10.1016/j.chb.2015.02.008

Jacobsen, W. C., \& Forste, R. (2011). The wired generation: Academic and social outcomes of electronic media use among university students. Cyberpsychology, Behavior, and Social Networking, 14(5), 275-280. https://doi.org/10.1089/cyber.2010.0135

Kaess, M., Parzer, P., Mehl, L., Weil, L., Strittmatter, E., Resch, F., \& Koenig, J. (2017). Stress vulnerability in male youth with Internet gaming disorder. Psychoneuroendocrinology, 77, 244-251. https://doi.org/10.1016/j.psyneuen.2017.01.008

Karaoğlan-Yılmaz, F. G., Yılmaz, R., Teker, N., \& Keser, H. (2014). Prediction of internet addiction of university students based on various variables.

Karasar, N. (2009). Bilimsel araştırma yöntemi: kavramlar-ilkeler-teknikler. Nobel Yayın Dağitim.

Kim, E. J., Namkoong, K., Ku, T., \& Kim, S. J. (2008). The relationship between online game addiction and aggression, self-control and narcissistic personality traits. European psychiatry, 23(3), 212-218. https://doi.org/10.1016/j.eurpsy.2007.10.010

Kim, N. R., Hwang, S. S.-H., Choi, J.-S., Kim, D.-J., Demetrovics, Z., Király, O., . . . Youn, H. C. (2016). Characteristics and psychiatric symptoms of Internet gaming disorder among adults using self-reported DSM-5 criteria. Psychiatry investigation, 13(1), 58.

King, D. L., \& Delfabbro, P. H. (2016). The cognitive psychopathology of Internet gaming disorder in adolescence. Journal of abnormal child psychology, 44(8), 1635-1645.

King, D. L., Delfabbro, P. H., Griffiths, M. D., \& Gradisar, M. (2011). Assessing clinical trials of Internet addiction treatment: A systematic review and CONSORT evaluation. Clinical Psychology Review, 31(7), 1110-1116. https://doi.org/10.1016/j.cpr.2011.06.009 
King, D. L., Delfabbro, P. H., Zwaans, T., \& Kaptsis, D. (2013). Clinical features and axis I comorbidity of Australian adolescent pathological Internet and video game users. Australian \& New Zealand Journal of Psychiatry, 47(11), 1058-1067. https://doi.org/10.1177/0004867413491159

Kuss, D. J., \& Griffiths, M. D. (2012). Internet gaming addiction: A systematic review of empirical research. International Journal of Mental Health and Addiction, 10(2), 278-296. https://doi.org/10.1089/cpb.2005.8.15

Liu, L., Yao, Y.-W., Li, C.-S. R., Zhang, J.-T., Xia, C.-C., Lan, J., . . Fang, X.-Y. (2018). The Comorbidity Between Internet Gaming Disorder and Depression: Interrelationship and Neural Mechanisms. Frontiers in psychiatry, 9, 154-154. https://doi.org/10.3389/fpsyt.2018.00154

Lo, S.-K., Wang, C.-C., \& Fang, W. (2005). Physical interpersonal relationships and social anxiety among online game players. Cyberpsychology \& behavior, 8(1), 15-20. https://doi.org/10.1089/cpb.2005.8.15

Lynch, J., Aughwane, P., \& Hammond, T. M. (2010). Video Games and Surgical Ability: A Literature Review. Journal of Surgical Education, 67(3), 184-189. https://doi.org/10.1016/j.jsurg.2010.02.010

Männikkö, N., Billieux, J., \& Kääriäinen, M. (2015). Problematic digital gaming behavior and its relation to the psychological, social and physical health of Finnish adolescents and young adults. Journal of behavioral addictions, 4(4), 281-288. https://doi.org/10.1556/2006.4.2015.040

Marchand, A., \& Hennig-Thurau, T. (2013). Value creation in the video game industry: Industry economics, consumer benefits, and research opportunities. Journal of Interactive Marketing, 27(3), 141-157. https://doi.org/10.1016/j.intmar.2013.05.001

Paulus, F. W., Ohmann, S., Von Gontard, A., \& Popow, C. (2018). Internet gaming disorder in children and adolescents: A systematic review. Developmental Medicine \& Child Neurology, 60(7), 645-659. https://doi.org/10.1111/dmen.13754

Petry, N. M., \& O’Brien, C. P. (2013). Internet gaming disorder and the DSM-5. Addiction, 108(7), 1186-1187. https://doi.org/10.1111/add.12162

Pontes, H. M., \& Griffiths, M. D. (2015). Measuring DSM-5 Internet gaming disorder: Development and validation of a short psychometric scale. Computers in Human Behavior, 45, 137-143. https://doi.org/10.1016/j.chb.2014.12.006

Quandt, T., Grueninger, H., \& Wimmer, J. (2009). The gray haired gaming generation: Findings from an explorative interview study on older computer gamers. Games and Culture, 4(1), 27-46. https://doi.org/10.1177/1555412008325480

Sahin, M., Gümüş, Y., \& Tofur, S. (2014). Game addiction and academic achievement. Educational Psychology, 36, 1533-1543. https://doi.org/10.1080/01443410.2014.972342

Stetina, B. U., Kothgassner, O. D., Lehenbauer, M., \& Kryspin-Exner, I. (2011). Beyond the fascination of online-games: Probing addictive behavior and depression in the world of online-gaming. Computers in Human Behavior, 27(1), 473-479. https://doi.org/10.1016/j.chb.2010.09.015

Sublette, V. A., \& Mullan, B. (2012). Consequences of play: A systematic review of the effects of online gaming. International Journal of Mental Health and Addiction, 10(1), 3-23.

Subramaniam, M., Chua, B. Y., Abdin, E., Pang, S., Satghare, P., Vaingankar, J. A., \& Chong, S. (2016). Prevalence and correlates of Internet gaming problem among Internet users: Results from an Internet survey. Annals of the Academy of Medicine, Singapore, 45(5), 174-183.

Toker, S., \& Baturay, M. H. (2016). Antecedents and consequences of game addiction. Computers in Human Behavior, 55, 668-679. https://doi.org/10.1016/j.chb.2015.10.002

Vadlin, S., Åslund, C., Hellström, C., \& Nilsson, K. W. (2016). Associations between problematic gaming and psychiatric symptoms among adolescents in two samples. Addictive behaviors, 61, 8-15. https://doi.org/10.1016/j.addbeh.2016.05.001

Wang, H. R., Cho, H., \& Kim, D.-J. (2018). Prevalence and correlates of comorbid depression in a nonclinical online sample with DSM-5 internet gaming disorder. Journal of affective disorders, 226, 1-5. https://doi.org/10.1016/j.jad.2017.08.005

Wong, H. (2011). A study of the video game industry in US metropolitan areas using occupational analysis.

Wright, J. (2011). The effects of video game play on academic performance. Modern Psychological Studies, 
$17(1), 6$.

Yılmaz, Ö., Boz, H., \& Arslan, A. (2017). Depresyon Anksiyete Stres Ölçeğinin (Dass 21) Türkçe Kisa Formunun Geçerlilik-Güvenilirlik Çalişmasi. Finans Ekonomi ve Sosyal Araştırmalar Dergisi (FESA), 2(2), 78-91.

\section{Copyrights}

Copyright for this article is retained by the author(s), with first publication rights granted to the journal.

This is an open-access article distributed under the terms and conditions of the Creative Commons Attribution license (http://creativecommons.org/licenses/by/4.0/). 